\title{
Structure and Microhardness of Cu-Ta Joints Produced by Explosive Welding
}

\author{
Iu. N. Maliutina, ${ }^{1}$ V. I. Mali, ${ }^{2}$ I. A. Bataev, ${ }^{1}$ A. A. Bataev, ${ }^{1}$ M. A. Esikov, ${ }^{2}$ \\ A. I. Smirnov, ${ }^{1}$ and K. A. Skorokhod ${ }^{1}$ \\ ${ }^{1}$ Novosibirsk State Technical University, Karl Marx Prospect 20, 630073 Novosibirsk, Russia \\ ${ }^{2}$ Lavrentyev Institute of Hydrodynamics, Siberian Branch, Russian Academy of Sciences, Akademika Lavrentyev Prospect 15, \\ 630090 Novosibirsk, Russia
}

Correspondence should be addressed to A. I. Smirnov; micros20t@mail.ru

Received 14 August 2013; Accepted 30 September 2013

Academic Editors: X. Cao, Y.-K. Gao, and Z. Zhou

Copyright (c) $2013 \mathrm{Iu}$. N. Maliutina et al. This is an open access article distributed under the Creative Commons Attribution License, which permits unrestricted use, distribution, and reproduction in any medium, provided the original work is properly cited.

\begin{abstract}
The structure and microhardness of $\mathrm{Cu}$-Ta joints produced by explosive welding were studied. It was found that, during explosive welding, an intermediate layer $20 \cdots 40 \mu \mathrm{m}$ thick with a finely dispersed heterophase structure, formed between the welded copper and tantalum plates. The structure of the layer was studied by scanning and transmission electron microscopy. Microvolumes with tantalum particles distributed in a copper matrix and microvolumes of copper particles in a tantalum matrix were detected. The tantalum particles in copper have a size of $5 \cdots 500 \mathrm{~nm}$, with a predominance of $5 \cdots 50 \mathrm{~nm}$ particles. A mechanism for the formation of the finely dispersed heterophase structure in explosive welding is proposed. The microhardness of interlayers with the heterophase structure reaches $280 \mathrm{HV}$, which far exceeds the microhardness of copper $(\sim 130 \mathrm{HV})$ and tantalum $(\sim 160 \mathrm{HV})$. Many twins of deformation origin were found in the structure of the copper plate. The effect of heating temperature in the range from 100 to $900^{\circ} \mathrm{C}$ on the microhardness of copper, tantalum, and the $\mathrm{Cu}$-Ta welded joint was studied. Upon heating to $900^{\circ} \mathrm{C}$, the microhardness of the intermediate layer decreases from 280 to $150 \mathrm{HV}$. The reduction in the strength properties of the weld material is mainly due to structural transformations in copper.
\end{abstract}

\section{Introduction}

One of the most essential problems of modern materials science is the development of reliable joints of dissimilar metals with significantly different physical and mechanical properties [1-3]. There are a number of efficient methods for producing composites of this type based on fusion welding. Welding of reactive metals often involves the formation of brittle phases, for example, intermetallic compounds, in the fused joint. This problem is encountered in joining of nickel and aluminum, aluminum and titanium, titanium and iron, and many others materials $[4,5]$. One of the most effective methods for preventing the formation of brittle chemical compounds is the application of diffusion barriers based on refractory metals, such as $\mathrm{Ta}, \mathrm{Nb}, \mathrm{V}$, and $\mathrm{W}$. Due to the large difference in physicochemical and mechanical properties between the welded dissimilar metals and refractory barriers, in some cases it is reasonable to produce intermediate barriers in the form of inserts by joining refractory metals with copper [6-8].

Below we consider in detail a $\mathrm{Cu}$-Ta system characterized by nearly zero mutual solubility of the components in the solid state $[9,10]$ and high structural stability and mechanical strength of the joint at elevated temperature. Wang et al. [11] note the absence of structural transformations and changes in mechanical properties of a sputter-deposited $\mathrm{Cu}$ Ta composite during heating at $900^{\circ} \mathrm{C}$ for $100 \mathrm{~h}$. Greenberg et al. $[12,13]$ have shown that explosive welding of materials with no mutual solubility results in the formation of a heterophase mixture in the joint region with particle sizes of the dispersed phase similar to those of colloids.

This paper deals with the structure and microhardness of welds produced by explosive welding of copper and tantalum plates followed by heat treatment. 


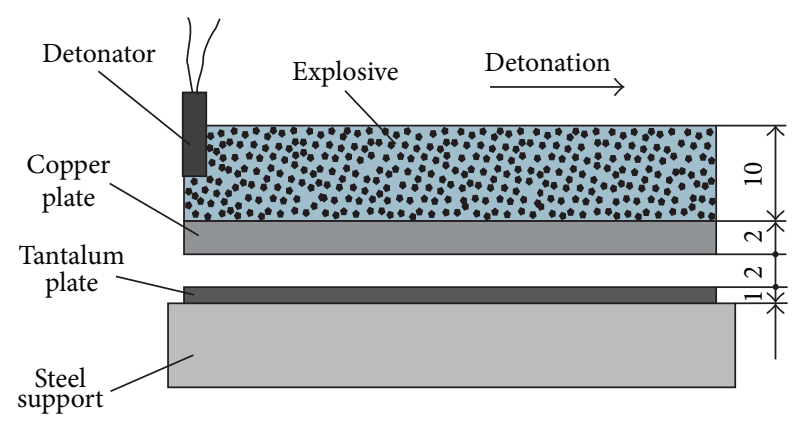

FIGURE 1: Schematic diagram of explosive welding with parallel arrangement of copper and tantalum plates.

\section{Materials and Methods}

For explosive welding we used plates of technically pure copper $(99.98 \% \mathrm{Cu})$ and tantalum $(99.95 \% \mathrm{Ta})$. The materials used are significantly different in structure, density, melting point, and thermal conductivity in (Table 1). These differences have a significant effect on the behavior of the materials during explosive welding.

Explosive welding of copper and tantalum plates arranged in parallel (Figure 1) was performed at the Lavrent'ev Institute of Hydrodynamics. A tantalum plate $1 \mathrm{~mm}$ thick was placed on a steel support. The flyer plate was a $2 \mathrm{~mm}$ copper plate. The distance between the copper and tantalum plates was set equal to $2 \mathrm{~mm}$. The explosive was $6 \mathrm{ZhV}$ ammonite of density $0.9 \mathrm{~g} \cdot \mathrm{cm}^{3}$, which was placed directly on the copper plate. The detonation velocity of the explosive was $3800 \mathrm{~m} \cdot \mathrm{s}^{-1}$, and the plate collision angle was $17^{\circ}$. Prior the welding the surfaces of the plates were grinded using $\mathrm{SiC}$ abrasive paper (320 grit).

The thermal stability of the $\mathrm{Cu}$-Ta joint was determined by annealing samples at temperatures in the range of 100 to $900^{\circ} \mathrm{C}$. The dwell time in the furnace was $1 \mathrm{~h}$. A characteristic feature of tantalum is its active interaction with the gases that make up the air. For this reason, the welded joints were annealed in a vacuum furnace at $10^{-6} \mathrm{~Pa}$.

Structural studies were performed on transverse sections. For metallographic studies and microhardness measurements, laminated composite specimens were cut along the direction of shock-wave propagation. Metallographic sections were prepared by conventional techniques comprising grinding and polishing. The structure of copper was revealed by etching in an aqueous solution of ferric chloride and hydrochloric acid.

Metallographic studies were carried out using a Carl Zeiss Axio Observer Z1m microscope. Subtle structural changes in plastically deformed materials were studied using a Tecnai G2 20 TWIN transmission electron microscope. The objects of study were foils. The foils were prepared by a technique combining cutting of samples with an electric spark machine, mechanical thinning to a thickness of $100 \mu \mathrm{m}$, dimple grinding using a Gatan Dimple Grinder, and final ion thinning in a Gatan PIPS 659 ion mill. The structure of the sample material in the region of interaction was studied using an EVO 50 XVP scanning electron microscope.

Microhardness of the samples was measured before and after heat treatment with a Wolpert Group 402 MVD

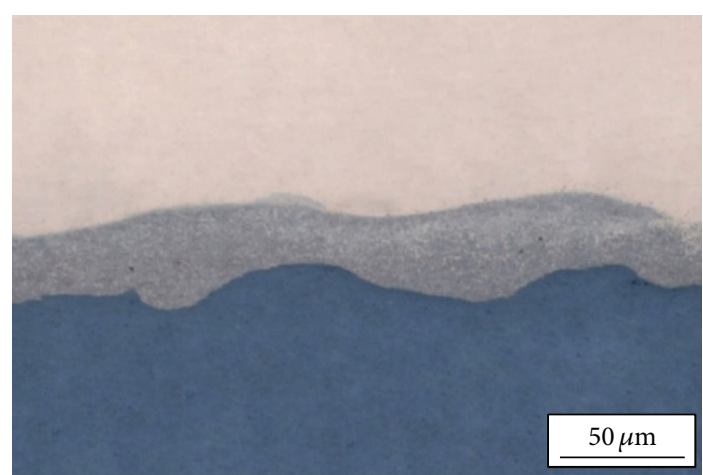

(a)

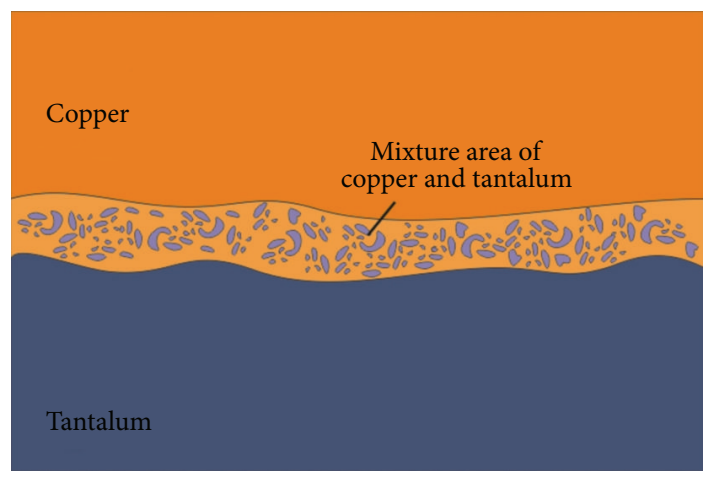

(b)

Figure 2: General view (a) and schematic diagram (b) of Cu-Ta joint produced by explosive welding.

TABLE 1: Some properties of copper and tantalum.

\begin{tabular}{lcc}
\hline Features & $\mathrm{Cu}$ & $\mathrm{Ta}$ \\
\hline Crystal lattice & $\mathrm{fcc}$ & $\mathrm{bcc}$ \\
Density, g/cm & 8,93 & 16,6 \\
Melting point, ${ }^{\circ} \mathrm{C}$ & 1084 & 2996 \\
Recrystallization temperature, ${ }^{\circ} \mathrm{C}$ & 300 & 1300 \\
Thermal conductivity, $\mathrm{W} / \mathrm{m} \cdot \mathrm{K}$ & 390 & 52.1 \\
\hline
\end{tabular}

microhardness tester. The load on the diamond indenter was $0.245 \mathrm{~N}$. The measurement procedure involved the creation of a track of indentations perpendicular to the weld in the direction from the copper layer to the tantalum layer. The indenter indentation were spaced at $50 \mu \mathrm{m}$ intervals.

\section{Results and Discussion}

3.1. Structural Analysis of the Explosively Welded Cu-Ta Joint. The structure and the scheme of the explosively welded $\mathrm{Cu}$ Ta joint in a longitudinal section are shown in Figure 2. The line of junction of the plates obtained under the welding conditions described in Section 2 does not have a regular wavy shape that is characteristic of many explosively welded metals. Formation of a wavy junction is prevented by the large differences in strength properties, density, and melting point between copper and tantalum. Optical metallography and scanning electron microscopy identified a continuous layer $20 \cdots 40 \mu \mathrm{m}$ thick between the copper and tantalum 


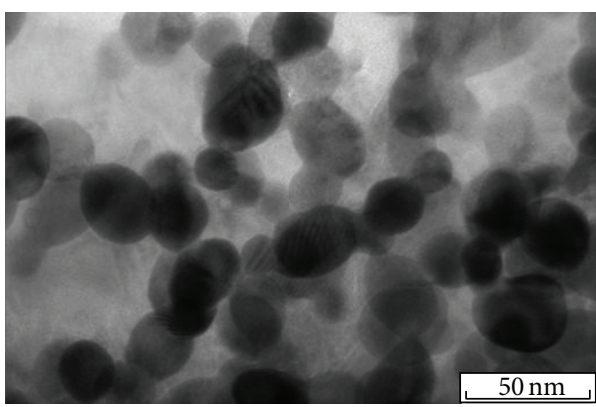

(a)

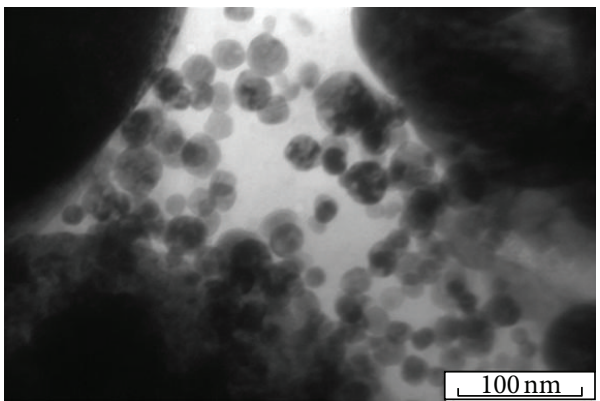

(c)

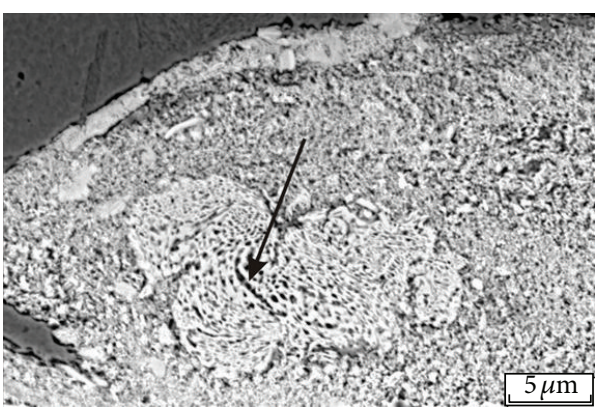

(e)

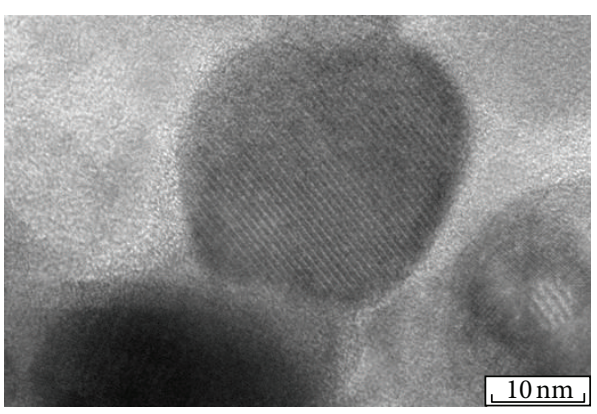

(b)

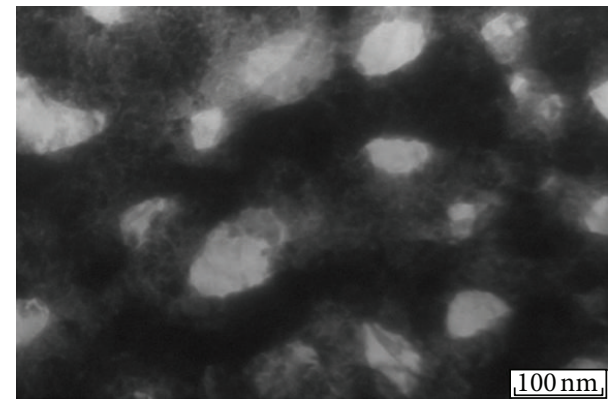

(d)

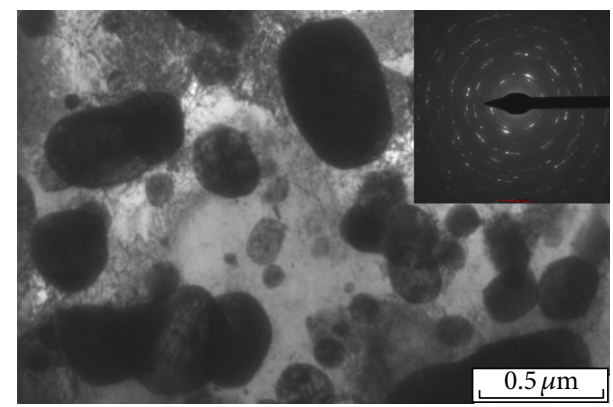

(f)

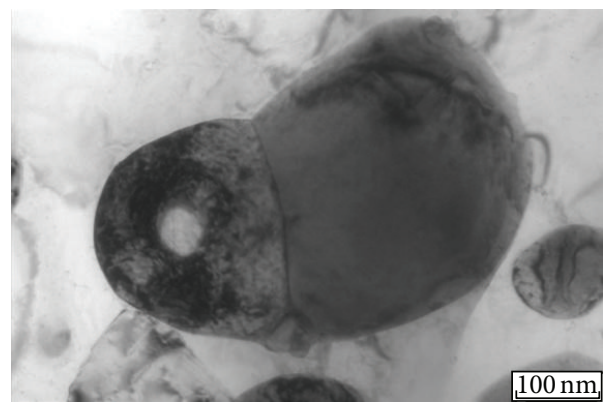

(g)

FIGURE 3: Structure of the intermediate layer with a heterophase structure after explosive welding of copper and tantalum plates (a-e) and after heating for 1 hour at $900^{\circ} \mathrm{C}(\mathrm{f}, \mathrm{g})$. (e) is a scanning electron micrograph, and the other images are transmission electron micrographs.

plates. The layer contains the material formed by mixing of the dissimilar materials under dynamic interaction. During the formation of wavy welds, such structure of a mixture of materials is observed only in the vortex zones formed near the crests and troughs of individual waves.

Due to the high degree of dispersion of the resulting mixture, it is difficult to determine the size and shape of individual elements of the structure in the layer by scanning electron microscopy. For this reason, a more detailed structural analysis of the mixing regions was performed using transmission electron microscopy. The main factors determining the structural features of the material are the high rates and amounts of strain in the surface layers of the plates, high heating temperatures of tantalum and copper in 


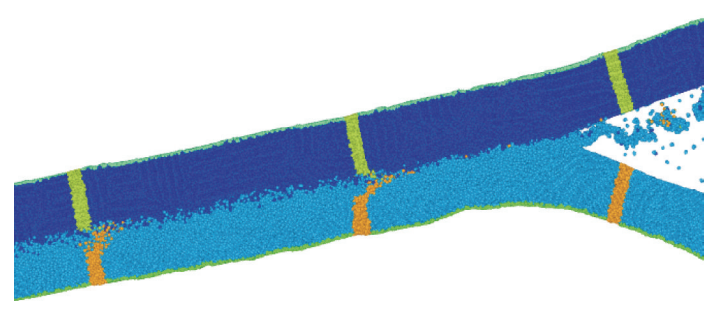

Figure 4: Direction of the jet in the collision of a copper plate (top) and an aluminum plate (bottom) simulated using a molecular dynamics model [14].

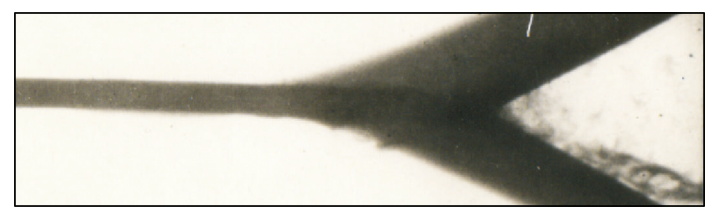

FIGURE 5: X-ray photograph of copper plate colliding with different velocities (the upper plate at a velocity $v_{n 2}=1.26 \mathrm{~km} / \mathrm{s}$ and the lower plate at a velocity $v_{n 1}=1.12 \mathrm{~km} / \mathrm{s}$ ) [15].

the contact area, and the presence of a cumulative sheet of fine particles of the interacting materials.

In general, the structure of the intermediate heterophase layer can be defined as a mixture of fine copper and tantalum. The matrix material in the layer, characterized by continuity, is predominantly copper. A lot of dark rounded particles of tantalum can be seen against the background of the bright copper matrix. Tantalum particles in copper have sizes of $5 \cdots 500 \mathrm{~nm}$, with a predominance of $5 \cdots 50 \mathrm{~nm}$ particles (Figures 3(a) and 3(b)). An example of a combination of a finely dispersed structure with larger particles of tantalum is presented in Figure 3(c).

In addition, the heterophase layer was experimentally found to contain microvolumes in which the matrix material is tantalum and copper is in the form of separate islands. A transmission electron micrograph of a structure of this type is shown in Figure 3(d). The copper particle size is $\sim 50 \cdots 100 \mathrm{~nm}$. Figure 3(e) shows a scanning electron micrograph of the structure of the intermediate layer. The microvolume of tantalum with copper particles is indicated by the arrow.

The mechanism of formation of the intermediate heterophase layer can be described as follows (Figures 4 and 5). During dynamic interaction of copper and tantalum plates, a discrete cumulative jet consisting mainly of fragments of copper is formed at the point of contact. It is known $[14,15]$ that if the colliding metals differ greatly in density or velocity, the discrete jet does not move along the bisector of the collision angle but is deflected toward the denser (in our case, tantalum) or slow-moving plate.

It should be emphasized that the surface of the joined plates is rough. The size of the majority of particles in the gap between the joined plates $(5 \cdots \sim 50 \mathrm{~nm})$ is $2 \cdots 3$ orders of magnitude smaller than the roughness values of the metal workpieces. Thus, some of the highly dispersed particles

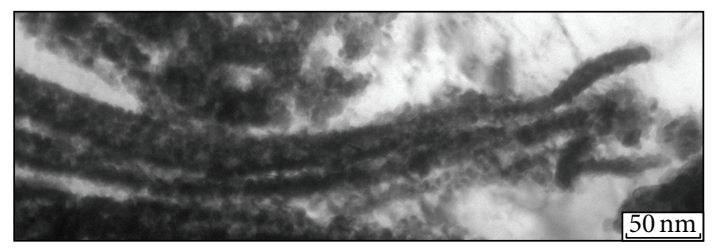

FIGURE 6: Banded clusters of tantalum in copper.

moving faster than the point of contact $>3800 \mathrm{~m} \cdot \mathrm{s}^{-1}$ penetrate into the rough surface layers of the tantalum plate.

The impact of the jet fragments on the surface layers of the tantalum plate leads to the formation of a mixing zone and a cloud of fine particles of a mixture of copper and tantalum. Most of the tantalum particles in the mixing zone are randomly distributed in copper. Note that the melting points of copper and tantalum differ by almost a factor of three $\left(1084^{\circ} \mathrm{C}\right.$ and $\left.2996^{\circ} \mathrm{C}\right)$. Tantalum particles remain in the solid state under such collisions. At the same time, microvolumes of copper with ordered arrangement of tantalum particles are also observed. The tantalum clusters shown in Figure 6 have a banded form. Structural analysis performed at higher magnifications indicates that the elongated structures observed in the micrographs consist of individual nanosized particles of tantalum. It can be suggested that their formation results from the flow of a discrete copper jet on a rough surface of tantalum, whose fragments are stretched by the high-velocity flow.

3.2. Thermal Stability of the Cu-Ta Welded Joint. The thermal stability of the $\mathrm{Cu}$-Ta joint was evaluated by heating the samples with subsequent analysis of structural changes and microhardness of the materials. The heating temperature was in the range of $100 \cdots 900^{\circ} \mathrm{C}$. The exposure at each temperature was $1 \mathrm{~h}$.

Increase in the heating temperature was accompanied by structural transformations, leading to strength degradation of the copper and tantalum plates and the heterophase layer located between them. Structural analysis revealed the most pronounced changes in the copper plate. In the initial state (before welding), the grain size was $22 \mu \mathrm{m}$. Dynamic interaction between the plates leads to deformation strengthening of copper in regions directly adjacent to the weld. This is indicated by the formation of microvolumes with increased dislocation density (Figure 7(a)) and a set of twins of deformational origin. Typically, twins $\sim 10 \cdots 50 \mathrm{~nm}$ wide are arranged in the form of individual stacks (Figure $7(b)$ ). Figures $7(\mathrm{~b})-7(\mathrm{~d})$ shows bright- (b) and dark-field images of the same region of plastically deformed copper. Twinning deformation is typical of metals under high-velocity deformation, including explosive welding $[16,17]$.

The most notable changes in the strength properties of the plastically deformed materials occur upon heating to values close to the recrystallization temperature. After heating to $500^{\circ} \mathrm{C}$, the copper plate has no indications of recrystallization. During heating to $600^{\circ} \mathrm{C}$, the recrystallization of copper is nonuniform. Recrystallization occurs in islands spaced at $2000 \mu \mathrm{m}$ intervals along the surface of junction of the 


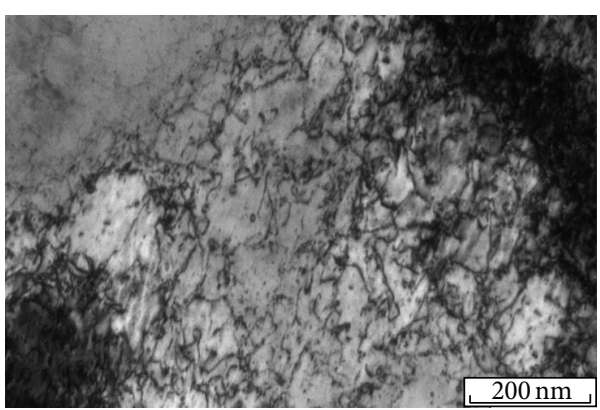

(a)

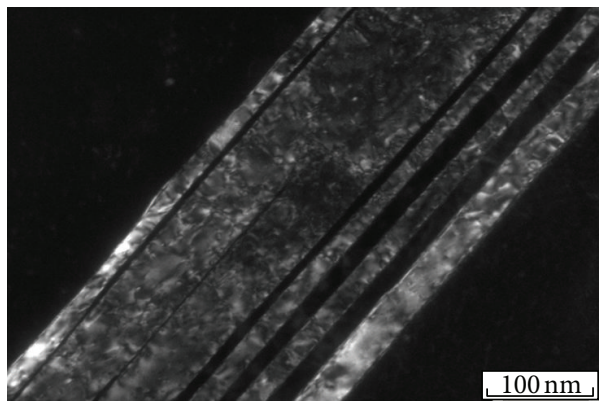

(c)

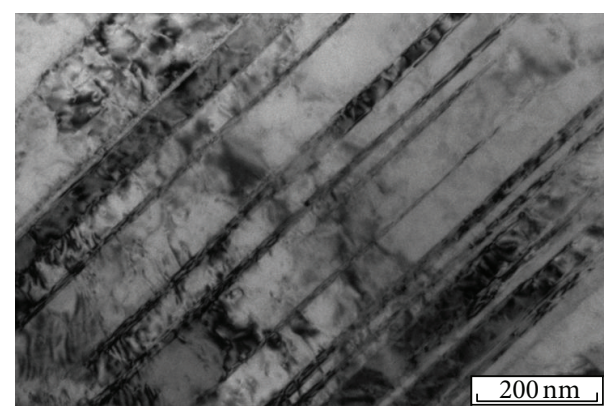

(b)

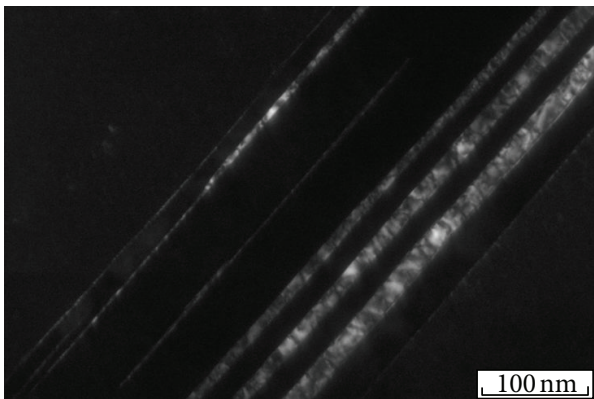

(d)

FIGURE 7: Dislocation structure (a) and twins of deformation origin (b-d) in a copper plate at a distance of $50 \mu \mathrm{m}$ from the intermediate layer. (b) bright-field and (c, d) dark-field transmission electron micrographs of the same section.

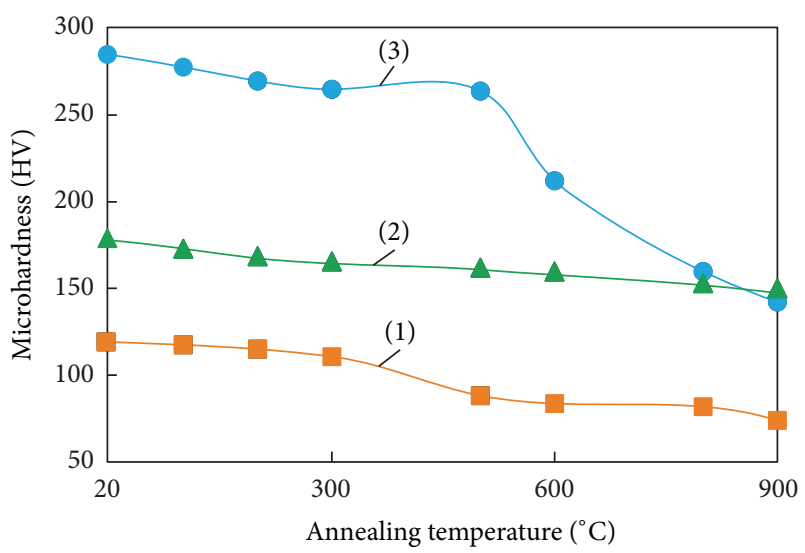

FIGURE 8: Effect of heating temperature on the microhardness of copper (1), tantalum (2), and the intermediate layer with a heterophase structure (3).

plates. It should be noted that in the copper layer, strain far exceeding the critical value occurs at a depth of several tens of micrometers. In the rest of the volume of the copper plate, the amount of strain is close to the critical value. For this reason, copper recrystallization is accompanied by a sharp increase in the grain size. After heating to $700^{\circ} \mathrm{C}$, the grain size in the recrystallized zones is $440 \mu \mathrm{m}$. In the samples exposed at $900^{\circ} \mathrm{C}$ for $1 \mathrm{~h}$, the grain size increased to $620 \mu \mathrm{m}$.

Results of microhardness measurements of thermally untreated samples of welded joints and those annealed at various temperatures are presented in Figures 8 and 9.

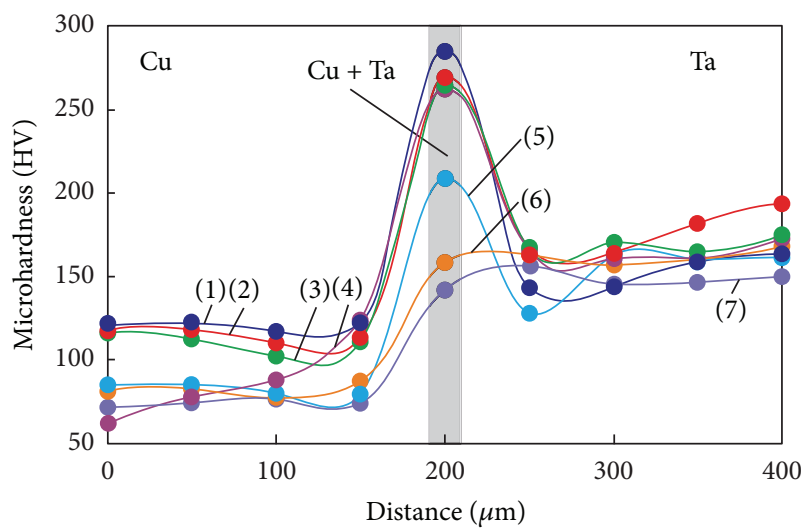

FIGURE 9: Microhardness of the intermediate layer and its adjacent regions after explosive welding of copper and tantalum plates and subsequent heating of the weld at different temperatures. (1) without heat treatment, (2) heating to $200^{\circ} \mathrm{C}$, (3) $300^{\circ} \mathrm{C}$, (4) $500^{\circ} \mathrm{C}$, (5) $600^{\circ} \mathrm{C}$, (6) $800^{\circ} \mathrm{C}$, and $(7) 900^{\circ} \mathrm{C}$.

Microhardness was measured in a direction perpendicular to the welded joint within $200 \mu \mathrm{m}$ on each side of the plane of junction of the plates. The highest microhardness values were recorded for thermally untreated welded joints. After explosive welding, the microhardness of copper was $\sim 130 \mathrm{HV}$, and that of tantalum as $\sim 160 \mathrm{HV}$. Maximum microhardness $(280 \mathrm{HV})$ was recorded in the narrow intermediate layer of heterophase structure.

The observed effect of hardening of the material is probably due to the formation of a highly dispersed mixture 
and strain hardening of tantalum. Despite the large amount of plastic strain in the surface layer of the copper plate, strain hardening does not play a significant role in this case. Rapid heating of local microvolumes of the materials leads to melting of copper and eliminates the dislocations structure formed in the zone of dynamic interaction of the plates. The strain hardening effect is eliminated not only by melting but also upon reaching a temperature leading to recrystallization processes. These processes are typical of explosive welding of metallic materials [17-19]. During welding of carbon and alloy steels, a sharp increase in the strength properties in the weld zones is due to the hardening mechanism and the formation of a martensitic structure. In the $\mathrm{Cu}-\mathrm{Ta}$ system, with no mutual solubility of the elements, this mechanism cannot lead to an increase in the microhardness of the material in the weld zone.

In samples heated to $500^{\circ} \mathrm{C}$, the microhardness in the zone of mixing of tantalum and copper does not change significantly. This indicates that the heterophase structure is thermally stable in this temperature range. Heating to $600^{\circ} \mathrm{C}$ or above results in a marked decrease in the microhardness of the material. After annealing at $900^{\circ} \mathrm{C}$, the microhardness of the intermediate layer with mixed structure becomes equal to the microhardness of the tantalum plate $(\sim 150 \mathrm{HV})$. In contrast to this layer, the temperature dependence corresponding to tantalum shows no changes. This is due to the fact that the recrystallization temperature of tantalum is more than $300^{\circ} \mathrm{C}$ higher than the maximum temperature of annealing of the welded joint. Increasing the annealing temperature of copper to $900^{\circ} \mathrm{C}$ leads to an almost twofold decrease in its microhardness (from 130 to $75 \mathrm{HV}$ ) due to relaxation processes in dynamically deformed zones and the formation of a more equilibrium structure than that of the initial one [20].

\section{Conclusions}

During explosive welding in the joint area of tantalum and copper, plates form an intermediate layer which has a heterophase structure and consist of a mixture of fragments of dissimilar materials. The matrix material is predominantly copper. Tantalum in copper is in the form of isolated particles. Less common are microvolumes in which the matrix is tantalum with copper particles embedded in it. Based on the sizes of the dispersed-phase particles observed in the intermediate layer, the material can be classified as a highly dispersed system. The size of tantalum particles is predominantly in the nanometer range $(\sim 5 \cdots 50 \mathrm{~nm})$, which corresponds to the size range of colloidal particles. A mechanism for the formation of this structure was proposed which involves the formation of a fragmented, mainly copper, cumulative jet ahead of the point of contact of the plates. The jet moves directly on the surface of the tantalum plate and interacts with the roughness of the latter. The $\mathrm{Cu}$-Ta mixing area is thermally stable upon heating to $500^{\circ} \mathrm{C}$. Annealing at $900^{\circ} \mathrm{C}$ leads to a decrease in the microhardness of the intermediate layer with the heterophase structure from $280 \mathrm{HV}$ to $150 \mathrm{HV}$.

\section{Highlights}

(1) Copper-tantalum bimetal was obtained by explosive welding.

(2) The intermediate layer contains tantalum particles of $5 \cdots 50 \mathrm{~nm}$.

(3) A mechanism for the formation of the layer based on the formation of a fragmented cumulative jet is proposed.

(4) The thermal stability of the $\mathrm{Cu}$-Ta joint is maintained up to $500^{\circ} \mathrm{C}$.

(5) Upon heating to $900^{\circ} \mathrm{C}$, the microhardness of the intermediate layer decreases from $280 \mathrm{HV}$ to $150 \mathrm{HV}$.

\section{References}

[1] F. Findik, "Recent developments in explosive welding," Materials \& Design, vol. 32, no. 3, pp. 1081-1093, 2011.

[2] N. Kahraman and B. Gülenç, "Microstructural and mechanical properties of $\mathrm{Cu}-\mathrm{Ti}$ plates bonded through explosive welding process," Journal of Materials Processing Technology, vol. 169, no. 1, pp. 67-71, 2005.

[3] I. A. Bataev, D. V. Pavlyukova, T. V. Zhuravina, E. B. Makarova, and D. S. Terent'ev, "Explosive welding of laminated composite materials from dissimilar steels," Obrabotka Metallov: Tekhnologiya, Oborudovanie, Instrumenty, no. 1, pp. 6-8, 2010.

[4] I. A. Bataev, A. A. Bataev, V. I. Mali, and D. V. Pavliukova, "Structural and mechanical properties of metallic-intermetallic laminate composites produced by explosive welding and annealing," Materials \& Design, vol. 35, pp. 225-234, 2012.

[5] S. A. A. Akbari Mousavi and P. F. Sartangi, "Effect of post-weld heat treatment on the interface microstructure of explosively welded titanium-stainless steel composite," Materials Science and Engineering A, vol. 494, no. 1-2, pp. 329-336, 2008.

[6] S. I. Hong and M. A. Hill, "Microstructural stability of $\mathrm{Cu}-\mathrm{Nb}$ microcomposite wires fabricated by the bundling and drawing process," Materials Science and Engineering A, vol. 281, no. 1-2, pp. 189-197, 2000.

[7] R.-S. Lei, M.-P. Wang, M.-X. Guo, Z. Li, and Q.-Y. Dong, "Microstructure evolution and thermal stability of nanocrystalline $\mathrm{Cu}-\mathrm{Nb}$ alloys during heat treatment," Transactions of Nonferrous Metals Society of China, vol. 19, no. 2, pp. 272-276, 2009.

[8] H. Li, J. L. Chen, J. G. Li, and Z. X. Li, "High heat load properties of actively cooled tungsten/copper mock-ups by explosive joining," Journal of Nuclear Materials, vol. 363-365, no. 1-3, pp. 1226-1230, 2007.

[9] K. A. Darling, A. J. Roberts, Y. Mishin, S. N. Mathaudhu, and L. J. Kecskes, "Grain size stabilization of nanocrystalline copper at high temperatures by alloying with tantalum," Journal of Alloys and Compounds, vol. 573, pp. 142-150, 2013.

[10] T. Frolov, K. A. Darling, L. J. Kecskes, and Y. Mishin, "Stabilization and strengthening of nanocrystalline copper by alloying with tantalum," Acta Materialia, vol. 60, no. 5, pp. 2158-2168, 2012.

[11] H. Wang, M. J. Zaluzec, and J. M. Rigsbee, "Microstructure and mechanical properties of sputter-deposited Cul-xTax alloys," Metallurgical and Materials Transactions A, vol. 28, no. 4, pp. 917-925, 1997. 
[12] B. A. Greenberg, M. A. Ivanov, V. V. Rybin et al., “The problem of intermixing of metals possessing no mutual solubility upon explosion welding (Cu-Ta, Fe-Ag, Al-Ta)," Materials Characterization, vol. 75, pp. 51-62, 2013.

[13] B. A. Greenberg, M. A. Ivanov, V. V. Rybin et al., "Inhomogeneities of the interface produced by explosive welding," Physics of Metals and Metallography, vol. 113, no. 2, pp. 176-189, 2012.

[14] S. P. Kiselev and V. I. Mali, "Numerical and experimental modeling of jet formation during a high-velocity oblique impact of metal plates," Combustion, Explosion, and Shock Waves, vol. 48, no. 2, pp. 214-225, 2012.

[15] V. I. Mali, I. A. Bataev, A. A. Bataev, D. V. Pavlyukova, and E. A. Prikhod'ko, "Geometric transformations of sheet blanks during explosive welding of multilayer packets," Fizicheskaya Mezomekhanika, vol. 14, no. 6, pp. 117-124, 2011.

[16] I. A. Balagansky, K. Hokamoto, P. Manikandan et al., "Mach stem formation in explosion systems, which include high modulus elastic elements," Journal of Applied Physics, vol. 110, no. 12, Article ID 123516, 2011.

[17] I. Bataev, A. Bataev, V. I. Mali, M. Esikov, and V. Bataev, "Peculiarities of weld seams and adjacent zones structures formed in process of explosive welding of sheet steel plates," Materials Science Forum, vol. 673, pp. 95-100, 2011.

[18] I. A. Bataev, A. A. Bataev, V. I. Mali, V. G. Burov, and E. A. Prikhod'ko, "Formation and structure of vortex zones arising upon explosion welding of carbon steels," Physics of Metals and Metallography, vol. 113, no. 3, pp. 233-240, 2012.

[19] I. Bataev, A. Bataev, V. Mali et al., "Structure and fatigue crack resistance of multilayer materials produced by explosive welding," Advanced Materials Research, vol. 287-290, pp. 108111, 2011.

[20] F. J. Humphreys and M. Hatherly, Recrystallization and Related Annealing Phenomena, Elsevier, New York, NY, USA, 2nd edition, 2004. 

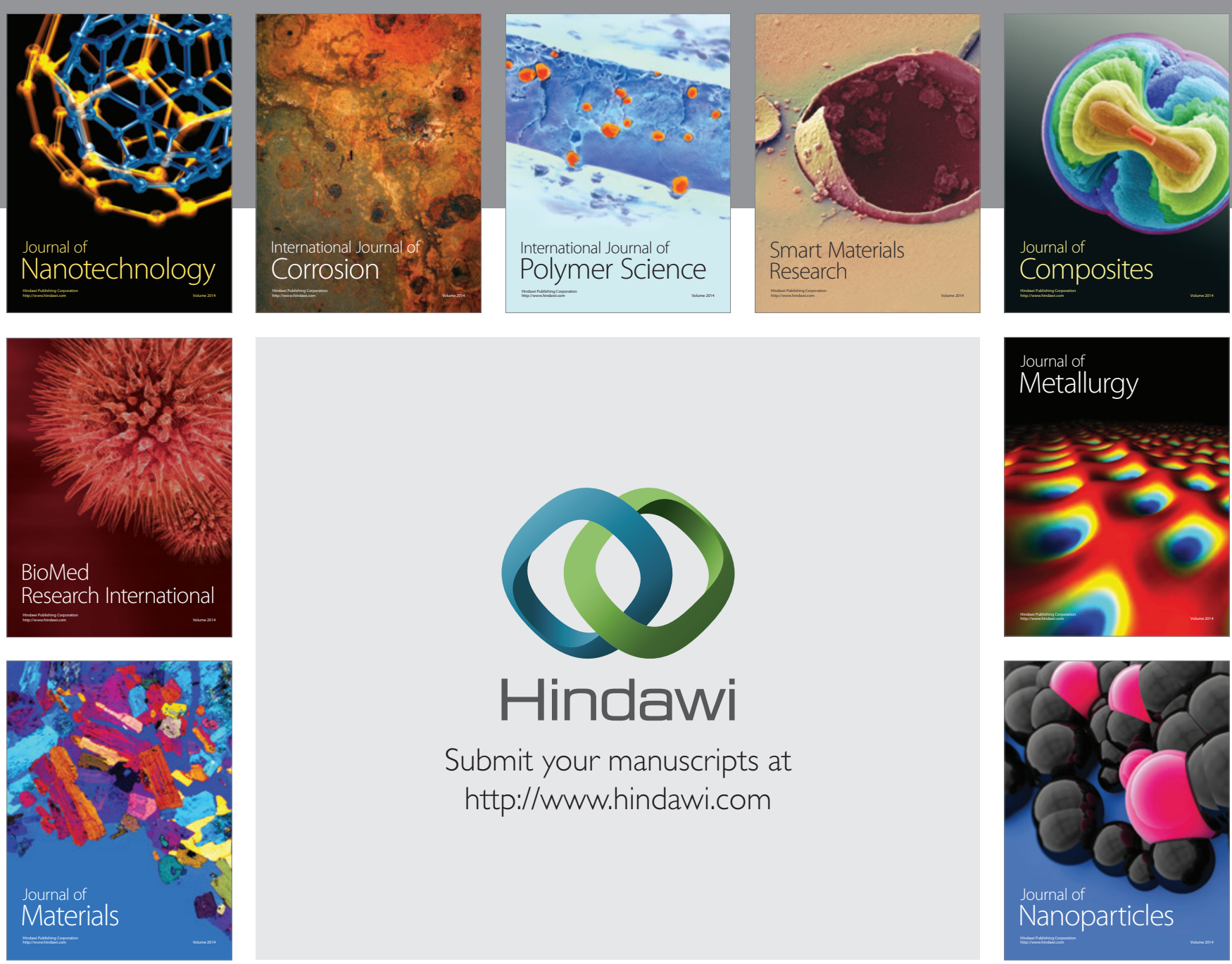

Submit your manuscripts at http://www.hindawi.com
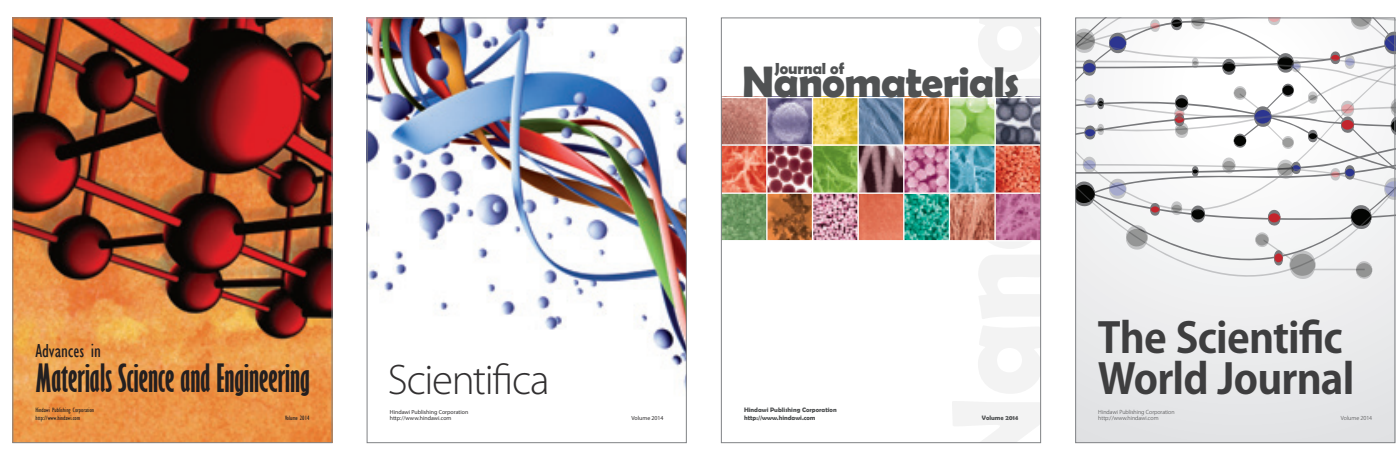

\section{The Scientific World Journal}
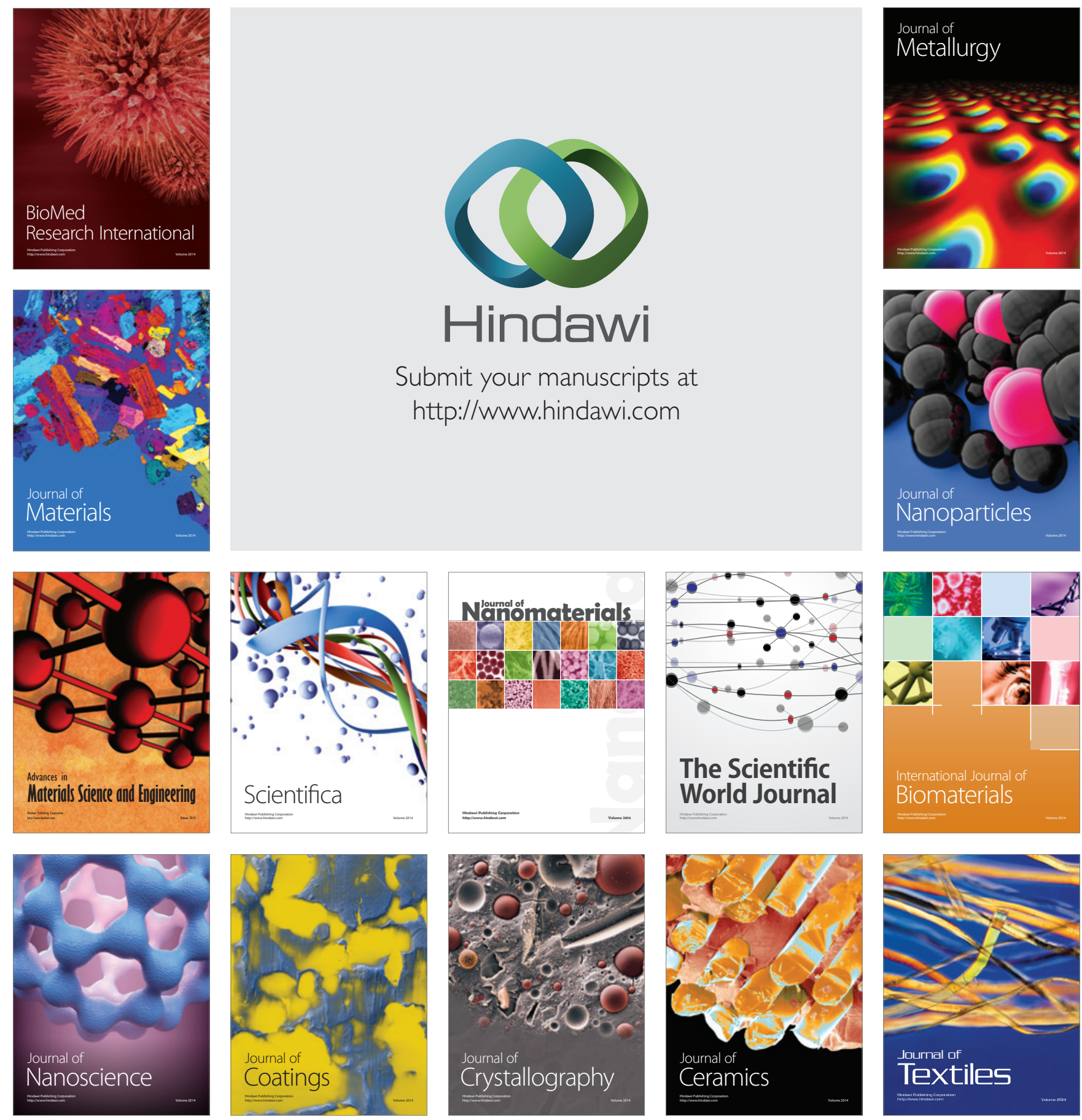